\title{
Influence of container structures and content solutions on dispensing time of ophthalmic solutions
}

This article was published in the following Dove Press journal:

Clinical Ophthalmology

14 May 2010

Number of times this article has been viewed

\author{
Keiji Yoshikawa' \\ Hiroshi Yamada ${ }^{2}$ \\ 'Yoshikawa Eye Clinic, Tokyo, Japan; \\ ${ }^{2}$ Santen Pharmaceutical Co., Ltd. \\ Osaka, Japan
}

Purpose: To investigate the influence of container structures and content solutions on the time of dispensing from eye dropper bottles.

Methods: Eye dropper bottle models, solution models (filtrate water/surfactant solution) and a dispensing time measuring apparatus were prepared to measure the dispensing time.

Results: With filtrate water and pressure thrust load of $0.3 \mathrm{MPa}$, the dispensing time significantly increased from $1.1 \pm 0.5$ seconds to $4.6 \pm 1.1$ seconds depending on the decrease of inner aperture diameters from $0.4 \mathrm{~mm}$ to $0.2 \mathrm{~mm}(P<0.0001)$. When using the bottle models with inner aperture diameters of $0.4 \mathrm{~mm}$ or larger, the dispensing time became constant. The dispensing time using surfactant solution showed the same tendency as above. When pressure thrust load was large $(0.07 \mathrm{MPa})$, the solution flew out continuously with inner aperture diameters of $0.4 \mathrm{~mm}$ or larger and the dispensing time could not be measured. The inner aperture diameter most strongly explained the variation of the dispensing time in both the content solutions in the multiple linear regression analysis (filtrate water: $46 \%, R^{2}=0.462$, surfactant solution: $56 \%, R^{2}=0.563$ ).

Conclusions: Among content solutions and container structures, the dispensing time was mostly influenced by the diameter of the inner aperture of bottles.

Keywords: dispensing time, model eye dropper bottle, model ophthalmic solution, nozzle internal space volume, nozzle inner aperture diameter

\section{Introduction}

Unlike internal medicines, ophthalmic solutions should be directly administered to the affected part (eyes) by patients themselves with controlling an eye dropper bottle. In long-term treatments with ophthalmic solutions for diseases such as glaucoma, "understanding of disease conditions" and "cost-effectiveness of an ophthalmic solution" might influence the patient adherence (ie, continuous treatment). Especially in the elderly, "operability of eye dropper bottles" influenced the instillation movements. ${ }^{1,2}$ In addition, to keep "cost-effectiveness of ophthalmic solutions", several factors such as the size and hardness of eye dropper bottles and the nozzle shape have been investigated. ${ }^{3-6}$

"The optimal drop size" is used as a measure in these studies. The optimal drop size directly reflects the container structures (eg, nozzle shape and internal air pressure of containers) $)^{7-10}$ and characteristics of fluid elements (eg, surface tension of ophthalmic solutions). Appropriateness of the optimal drop size is also related to cost-effectiveness. However, few investigators have focused on the dispensing time, which is the time from when users press an eye dropper bottle until when a drop enters into the eye, as a factor which may affect "the operability of eye dropper bottles".
Yoshikawa Eye Clinic, I-3-I Nakamachi

Machida, Tokyo 194-002I, Japan

Tel $+8 \mid 42739078$

Fax $+8 I 427390782$

Email keiyomd@aol.com 
If the dispensing time was not maintained constant by the eye dropper bottle, there was a high possibility of disturbing appropriate instillation of ophthalmic solutions to the eye surface (ie, operability); which would consequently influence the cost effectiveness. Therefore, we should investigate the factors of eye dropper bottles that were related to the dispensing time.

In this study, we prepared eye dropper bottle models and solution models, and newly developed a dispensing time measuring apparatus to investigate the influence of ophthalmic solutions and eye dropper containers on the dispensing time.

\section{Materials and methods}

Eye dropper bottle models and solution models were prepared. The eye dropper bottle models were made of polyethylene resins, and were cylindrical-shaped with a dent on their trunk. Wall thickness of the bottle was $0.7 \mathrm{~mm}$, and bottle volume was $8 \mathrm{~mL}$ (Figure 1). Outer diameter of tip of the nozzle, which was a head of the eye dropper bottle, was standardized to be $3.1 \mathrm{~mm}$ (Figure 2). Concerning inner structure, the bottles had 6 different types of the shortest diameter of the aperture in the nozzle (diameter of inner aperture) (ie, $0.2 \mathrm{~mm}$, $0.3 \mathrm{~mm}, 0.4 \mathrm{~mm}, 0.5 \mathrm{~mm}, 0.6 \mathrm{~mm}$ and $0.7 \mathrm{~mm}$ ), and 3 different types of internal space volume of the nozzle (internal volume of the nozzle) (ie, $7 \mathrm{~mm}^{3}, 30 \mathrm{~mm}^{3}$ and $55 \mathrm{~mm}^{3}$ ).

We prepared the following two types of content solution filled in the eye dropper bottle models: filtrate water (Surface

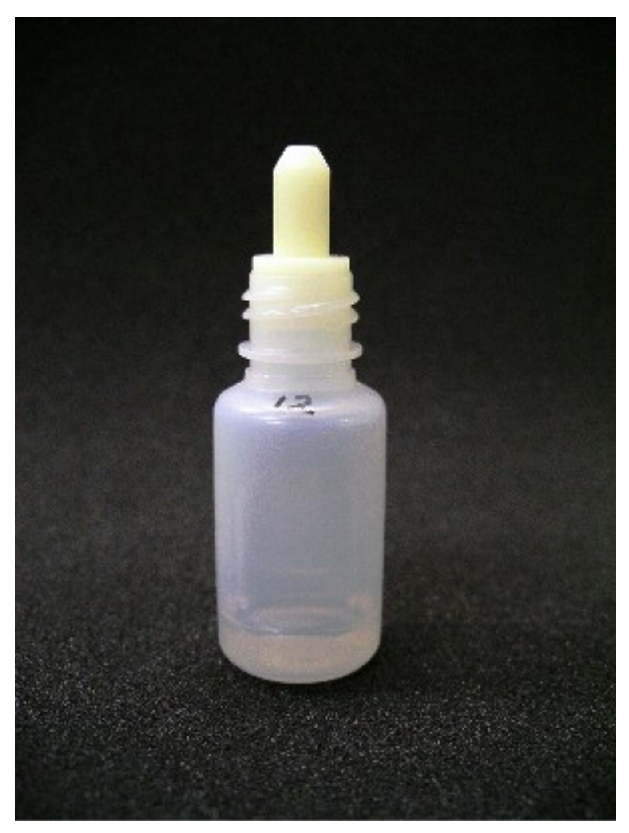

Figure I Eye dropper bottle.

Notes: The eye dropper bottle models were made of polyethylene resins, and were cylindrical-shaped with a dent on their trunk. Wall thickness of the bottle was $0.7 \mathrm{~mm}$, and bottle volume was $8 \mathrm{~mL}$.

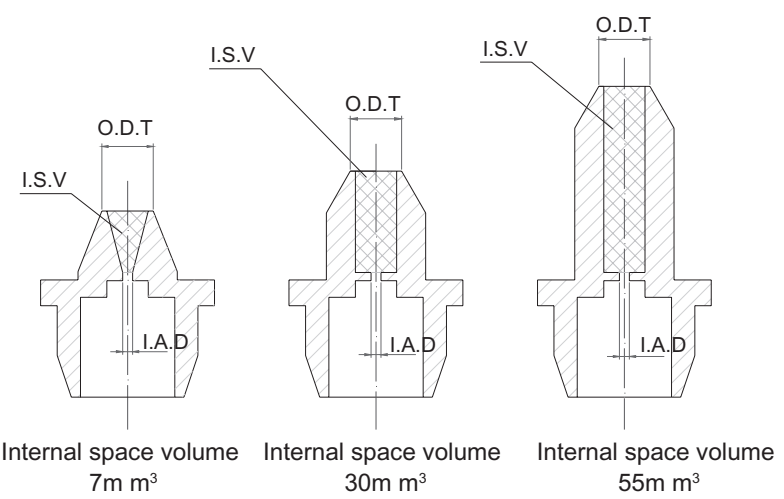

Figure 2 Structure of eye dropper bottle.

Notes: Outer diameter of the tip of model eye dropper nozzle was standardized to be $3.1 \mathrm{~mm}$. Concerning inner structure, the bottles had three different types of internal space volume of the nozzle $\left(7 \mathrm{~mm}^{3}, 30 \mathrm{~mm}^{3}\right.$ and $\left.55 \mathrm{~mm}^{3}\right)$ and six different inner aperture diameters $(0.2 \mathrm{~mm}, 0.3 \mathrm{~mm}, 0.4 \mathrm{~mm}, 0.5 \mathrm{~mm}, 0.6 \mathrm{~mm}$ and $0.7 \mathrm{~mm})$. In total, 18 patterns of nozzle models were molded.

Abbreviations: IAD, inner aperture diameter; ISV, internal space volume; ODT, outer diameter of tip.

tension: $72.8 \mathrm{mN} / \mathrm{m}$, Kinetic viscosity: $0.81 \mathrm{~mm}^{2} / \mathrm{s}$, Filtration system: Milli-Q PLUS (Millipore, Massachusetts, USA)) and 0.5\% surfactant solution (Surface tension: $39.4 \mathrm{mN} / \mathrm{m}$, Kinetic viscosity: $0.83 \mathrm{~mm}^{2} / \mathrm{s}$, Polysorbate 80 (Kao Corporation, Tokyo, Japan)). Surface tension was measured by an automatic surface tensiometer (CBVP-A3, Kyowa Interface Science Co., Ltd., Saitama, Japan), and kinetic viscosity by an Ubbelohde type viscometer. Five-, 3- and 1- mL of the test solution were filled in the eye dropper bottle models.

The time from when users pressed an eye dropper bottle until when a drop entered into the eye was defined as the dispensing time. The digital force gauge to measure squeeze strength (FGC-5: Nidec-Shimpo Corporation, Kyoto, Japan), which was previously reported by us, ${ }^{11}$ was modified to develop a dispensing time measuring apparatus (Unicon Co., Ltd., Ishikawa, Japan) (Figure 3) for this study. The eye dropper bottle model filled with the test solution was placed in the inverted position to the apparatus. The midsection of the bottle trunk was pressed by a metal rod $(10 \mathrm{~mm}$ in diameter) connected to an air cylinder, and a drop of solution was dribbled mechanically. The strength applied to the bottle could be changed by controlling the pressure to move the air cylinder (pressure thrust load). The metal rod of this apparatus was designed to push the container with a constant pressure. Namely, the speed to push the bottle changed depending on the degrees of resistance from the bottle. The digital force gauge, which was placed across the bottle from the air cylinder, detected the application of pressure and a timer counter was activated.

When the pressure in the bottle increased and a drop of solution was dribbled, an infrared ray sensor placed $40 \mathrm{~mm}$ below the tip of the bottle nozzle detected the drop and the 


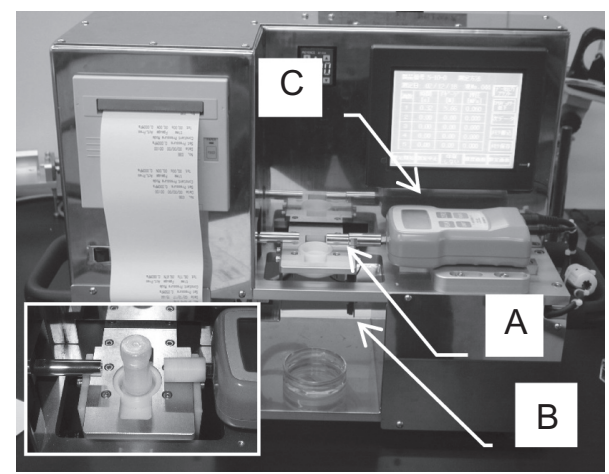

Figure 3 Dispensing time measuring apparatus.

Notes: A model bottle filled with the test solution was placed in the inverted position at the midportion between the site applied the pressure by a metal pressure $\operatorname{rod}(\mathrm{A} ; 10 \mathrm{~mm}$ in diameter) connected to an air cylinder and the tip of a digital force gauge (C). The midsection of the bottle trunk was pressed and a drop of solution was dribbled mechanically. Digital force gauge detected the application of pressure, and a timer counter was activated. After the pressure in the bottle increased and a drop of solution was dribbled, an infrared ray sensor (B) detected the drop and the timer counter stopped.

timer counter stopped. In the present study, the time from the start of pressure application until the passage of the solution through the infrared ray sensor was regarded as "the dispensing time". This apparatus was thought to experimentally recreate the dispensing time we defined. In experiments, three types of pressure thrust load (ie, $0.03 \mathrm{MPa}, 0.05 \mathrm{MPa}$ and $0.07 \mathrm{MPa}$ ) were applied. Using this apparatus, the dispensing time was measured 10 times for each experiment.

In statistical analysis, Tukey's honestly significant difference (HSD) test (Tukey's test) and step-wise multiple linear regression analysis were performed using SAS Version 9 (SAS Institute Inc., Cary, NC). $P$ values of less than 0.05 were considered to be statistically significant.

\section{Results}

The dispensing time was measured using the eye dropper bottle models with 6 types of diameter of inner aperture ( $0.2 \mathrm{~mm}, 0.3 \mathrm{~mm}, 0.4 \mathrm{~mm}, 0.5 \mathrm{~mm}, 0.6 \mathrm{~mm}$ and $0.7 \mathrm{~mm})$. Internal space volume of the nozzle of the bottle models was fixed to be $30 \mathrm{~mm}^{3}$, and fluid volume was $5 \mathrm{~mL}$. The experiment was performed with three types of pressure thrust load (0.03 MPa, 0.05 MPa and 0.07 MPa) and 2 types of solution (filtrate water and surfactant solution) (Figure 4).

When using filtrate water (Figure 4-A), the dispensing time at pressure thrust load of $0.03 \mathrm{MPa}$ was $4.6 \pm 1.1$ seconds with inner aperture diameter of $0.2 \mathrm{~mm}, 2.1 \pm 0.6$ seconds with $0.3 \mathrm{~mm}$, and $1.1 \pm 0.5$ seconds with $0.4 \mathrm{~mm}$; which showed significant differences in the dispensing time among the inner aperture diameters $(P<0.0001$ for $0.2 \mathrm{~mm}$ vs $0.3 \mathrm{~mm}$, $P<0.0037$ for $0.3 \mathrm{~mm}$ vs $0.4 \mathrm{~mm}$ ). On the other hand, there were no remarkable differences in the dispensing time among the inner aperture diameters of $0.4 \mathrm{~mm}(1.1 \pm 0.5$ seconds $)$,

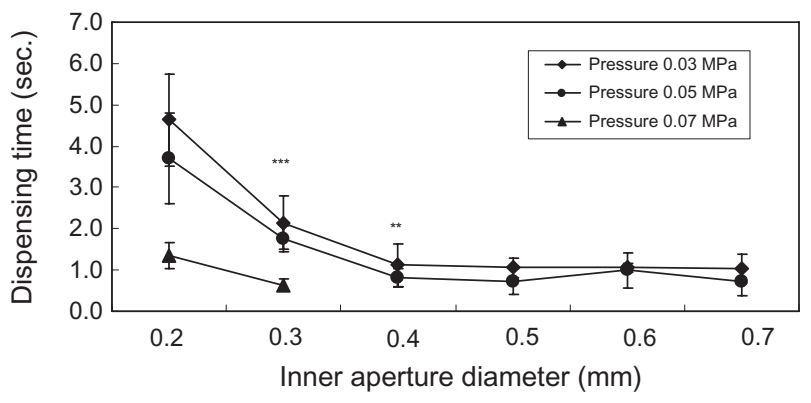

(A)

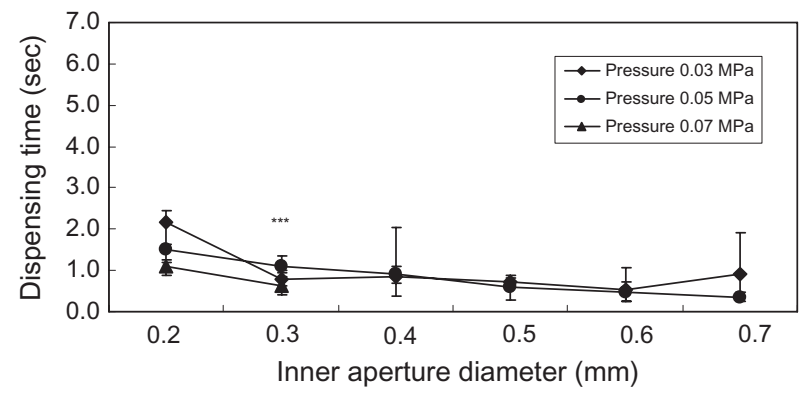

(B)

Figure 4 Dispensing time under condition of changing inner aperture diameter, thrust load pressure, and types of solution.

Notes: Mean dispensing time using fixed volumes of internal space $\left(30 \mathrm{~mm}^{3}\right)$ and fluid volume $(5 \mathrm{~mL})$, and variable inner aperture diameters (IADs) as well as pressures to the bottle (A: filtrate water, B: surfactant solution); error bars indicate standard deviation. Asterisks indicate statistically significant differences: $* * * P<0.001$; IAD of $0.2 \mathrm{~mm}$ vs IAD of $0.3 \mathrm{~mm}$, **P $<0.0$ I; IAD of $0.3 \mathrm{~mm}$ vs IAD of $0.4 \mathrm{~mm}$.

$0.5 \mathrm{~mm}(1.1 \pm 0.2$ seconds $), 0.6 \mathrm{~mm}(1.1 \pm 0.1$ seconds $)$ and $0.7 \mathrm{~mm}(1.0 \pm 0.3$ seconds $)(P=0.9999-P=1.0000)$. The dispensing time at pressure thrust load of $0.05 \mathrm{MPa}$ showed the same tendency as above. There were significant differences in dispensing time among the inner aperture diameters of $0.2 \mathrm{~mm}$ ( $3.7 \pm 1.1$ seconds $), 0.3 \mathrm{~mm}$ ( $1.8 \pm 0.3$ seconds $)$ and $0.4 \mathrm{~mm}(0.8 \pm 0.2$ seconds $)(P<0.0001$ for $0.2 \mathrm{~mm}$ vs $0.3 \mathrm{~mm}, P<0.0032$ for $0.3 \mathrm{~mm}$ vs $0.4 \mathrm{~mm}$ ). However, all bottle models with inner aperture diameters of $0.5 \mathrm{~mm}$ or larger showed the dispensing time of approximately 0.7 seconds, and there were no remarkable differences among the diameters $(P=0.8549-P=0.9992)$. At pressure thrust load of $0.07 \mathrm{MPa}$, there was a significant difference in dispensing time between the inner aperture diameters of $0.2 \mathrm{~mm}$ ( $1.4 \pm 0.3$ seconds $)$ and $0.3 \mathrm{~mm}(0.6 \pm 0.1$ seconds $)$ $(P<0.0001)$. The dispensing time could not be measured in the bottle models with inner aperture diameters of $0.4 \mathrm{~mm}$ or larger, since the solution flew out continuously.

When using surfactant solution (Figure 4-B), at pressure thrust load of $0.03 \mathrm{MPa}$, there was a significant difference in dispensing time between the inner aperture diameters of $0.2 \mathrm{~mm}(2.2 \pm 0.3$ seconds $)$ and $0.3 \mathrm{~mm}(0.8 \pm 0.1$ seconds $)$ $(P<0.0001)$. However, there was no remarkable difference in dispensing time between the diameters of $0.3 \mathrm{~mm}$ and $0.4 \mathrm{~mm}$ $(0.8 \pm 0.4$ seconds $)(P=0.9997)$. There were no significant 
differences in dispensing time among the inner aperture diameters of $0.5 \mathrm{~mm}(0.7 \pm 0.1$ seconds $), 0.6 \mathrm{~mm}$ ( $0.5 \pm 0.3$ seconds $)$ and $0.7 \mathrm{~mm}(0.9 \pm 0.4$ seconds $)(P=0.0612-P=0.9693)$.

Subsequently, the dispensing time at pressure thrust load of 0.05 MPa was measured using the eye dropper bottle models with three types of internal space volume of the nozzle $\left(7 \mathrm{~mm}^{3}, 30 \mathrm{~mm}^{3}\right.$ and $\left.55 \mathrm{~mm}^{3}\right)$ and three types of inner aperture diameter $(0.2 \mathrm{~mm}, 0.5 \mathrm{~mm}$ and $0.7 \mathrm{~mm})$ (Figure 5). When the test solution was filtrate water (Figure 5-A) and the inner aperture diameter was $0.2 \mathrm{~mm}$, the dispensing time was significantly lengthened as internal volume of the nozzle became larger $\left(1.6 \pm 0.4\right.$ seconds with internal volume of $7 \mathrm{~mm}^{3}$, $3.7 \pm 1.1$ seconds with $30 \mathrm{~mm}^{3}$, and $5.4 \pm 1.1$ seconds with $\left.55 \mathrm{~mm}^{3}\right)\left(7 \mathrm{~mm}^{3}\right.$ vs $30 \mathrm{~mm}^{3}: P=0.0056,30 \mathrm{~mm}^{3}$ vs $55 \mathrm{~mm}^{3}$ : $P=0.0219$ ). When the inner aperture diameter was $0.05 \mathrm{~mm}$, there was no significant difference in the dispensing time between internal nozzle volumes of $7 \mathrm{~mm}^{3}$ ( $0.5 \pm 0.2$ seconds) and $30 \mathrm{~mm}^{3}(0.7 \pm 0.3$ seconds $)(P=0.5448)$. The dispensing time with volumes of $7 \mathrm{~mm}^{3}$ and $30 \mathrm{~mm}^{3}$ significantly differed from that with $55 \mathrm{~mm}^{3}(1.8 \pm 0.9$ seconds $)\left(7 \mathrm{~mm}^{3}\right.$ vs $55 \mathrm{~mm}^{3}: P<0.0001,30 \mathrm{~mm}^{3}$ vs $\left.55 \mathrm{~mm}^{3}: P=0.0003\right)$.

(A)

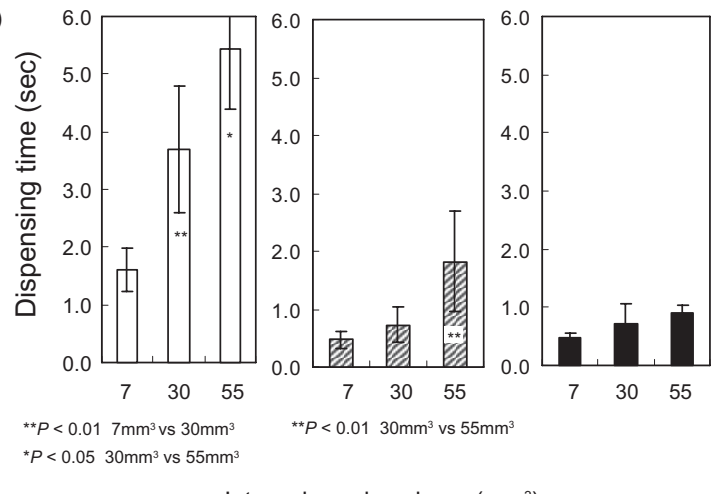

Internal nozzle volume $\left(\mathrm{mm}^{3}\right)$

(B)

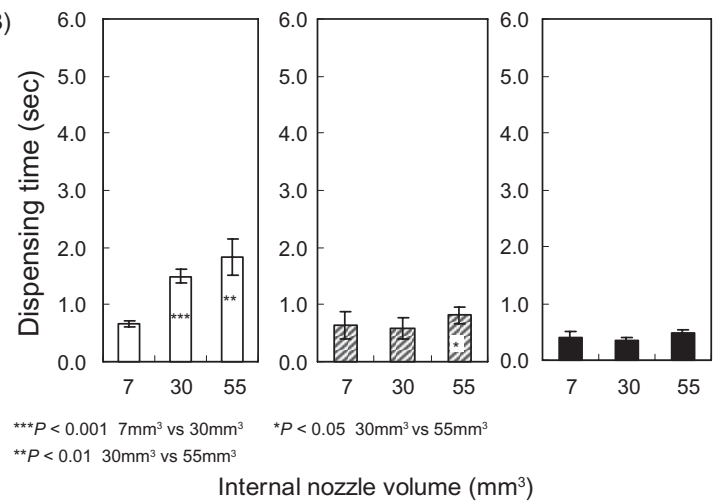

Figure 5 Dispensing time under condition of changing internal nozzle volume, inner aperture diameter, and types of solution.

Notes: Dispensing time (mean $\pm \mathrm{SD}$ ) under a condition of a fixed pressure thrust load $(0.05 \mathrm{MPa})$ and variable internal nozzle volumes and inner aperture diameters. ( $\square: 0.2 \mathrm{~mm}, \square: 0.5 \mathrm{~mm}, \square: 0.7 \mathrm{~mm}$ ) (A: filtrate water, B: surfactant solution); error bars indicate standard deviation. Asterisks indicate statistically significant differences: $* p<0.05$, $* * p<0.01$, $* * * p<0.001$.
When surfactant solution was used (Figure 5-B) and the inner aperture diameter was $0.2 \mathrm{~mm}$, there were significant differences in the dispensing time among internal nozzle volumes of $7 \mathrm{~mm}^{3}(0.7 \pm 0.1$ seconds), $30 \mathrm{~mm}^{3}(1.5 \pm 0.1$ seconds $)$ and $55 \mathrm{~mm}^{3}(1.8 \pm 0.3$ seconds) $\left(7 \mathrm{~mm}^{3}\right.$ vs $30 \mathrm{~mm}^{3}: P<0.0001,30 \mathrm{~mm}^{3}$ vs $\left.55 \mathrm{~mm}^{3}: P=0.0020\right)$. The significant difference in the dispensing time was observed between internal nozzle volumes of $30 \mathrm{~mm}^{3}(0.6 \pm 0.2$ seconds $)$ and $55 \mathrm{~mm}^{3}$ $(0.8 \pm 0.1$ seconds) with inner aperture diameter of $0.5 \mathrm{~mm}(P=0.0375)$, and between $30 \mathrm{~mm}^{3}(0.4 \pm 0.1$ seconds $)$ and $55 \mathrm{~mm}^{3}(0.5 \pm 0.1$ seconds $)$ with inner aperture diameter of $0.7 \mathrm{~mm}(P=0.0021)$.

We investigated the influence of fluid volume on the dispensing time by using eye dropper bottle models with three types of inner aperture diameter $(0.2 \mathrm{~mm}, 0.5 \mathrm{~mm}$, and $0.7 \mathrm{~mm})$ and three types of fluid volume $(1 \mathrm{~mL}, 3 \mathrm{~mL}$, and $5 \mathrm{~mL}$ ). Internal space volume of the nozzle and pressure thrust load were fixed to be $30 \mathrm{~mm}^{3}$ and $0.05 \mathrm{MPa}$, respectively (Figure 6).

When the test solution was filtrate water (Figure 6-A) and the inner aperture diameter was $0.2 \mathrm{~mm}$, the dispensing time was $3.0 \pm 0.7$ seconds at the fluid volume of $1 \mathrm{~mL}, 3.0 \pm 0.7$ seconds at $3 \mathrm{~mL}$ and $3.7 \pm 1.1$ seconds at $5 \mathrm{~mL}$ : which showed no significant differences $(P=0.9834$ for $1 \mathrm{~mL}$ vs $3 \mathrm{~mL}, P=0.7606$ for $3 \mathrm{~mL}$ vs $5 \mathrm{~mL}$ ). With inner aperture diameters of $0.5 \mathrm{~mm}$ and $0.7 \mathrm{~mm}$, the mean dispensing time remained within the range of 0.5 0.7 seconds even when fluid volume was changed, and no significant differences among fluid volumes were observed $(P=0.1195-P=1.0000)$. When surfactant solution was used (Figure 6-B) and the inner aperture diameter was $0.2 \mathrm{~mm}$, the dispensing time was significantly shortened depending on the fluid volume $(2.4 \pm 0.2$ seconds at $1 \mathrm{~mL}$, $1.8 \pm 0.1$ seconds at $3 \mathrm{~mL}, 1.5 \pm 0.1$ seconds at $5 \mathrm{~mL}$; $1 \mathrm{~mL}$ vs $3 \mathrm{~mL}: P=0.0064,3 \mathrm{~mL}$ vs $5 \mathrm{~mL}: P=0.0154$ ). With inner aperture diameters of $0.5 \mathrm{~mm}$ and $0.7 \mathrm{~mm}$, the mean dispensing time was $0.3-0.6$ seconds, and no significant differences among fluid volumes were observed $(P=0.6325-P=0.9664)$.

Multiple linear regression analysis was performed regarding the dispensing time as a response variable, and inner aperture diameter, internal space volume of the nozzle, pressure thrust load and fluid volume as the explanatory variables (Table 1). The inner aperture diameter most strongly explained the variation of the dispensing time in both filtrate water $\left(46 \%, R^{2}=0.462\right)$ and surfactant solution $\left(56 \%, R^{2}=0.563\right)$. Other variables could explain less than $10 \%$ of the variation. 


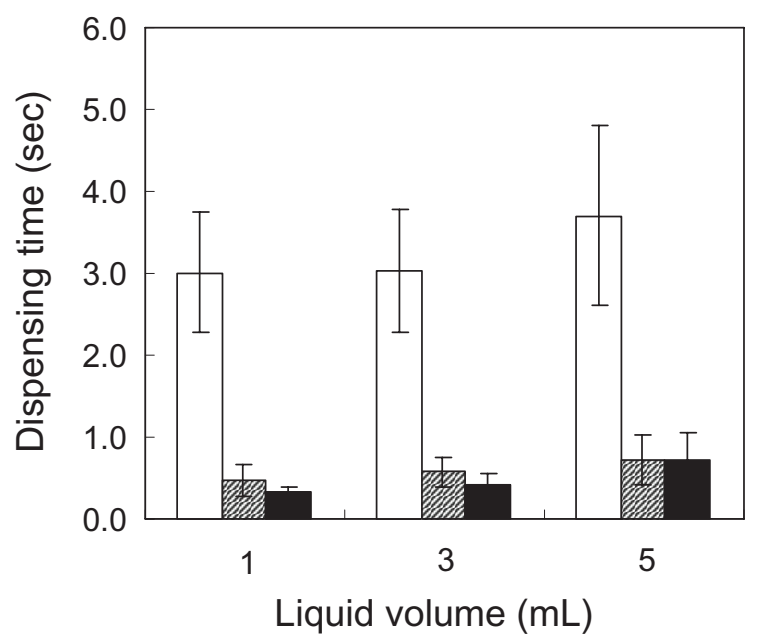

$\square \varphi 0.2 \mathrm{~mm} \quad \square 0.5 \mathrm{~mm} \quad \square 0.7 \mathrm{~mm}$

(A)

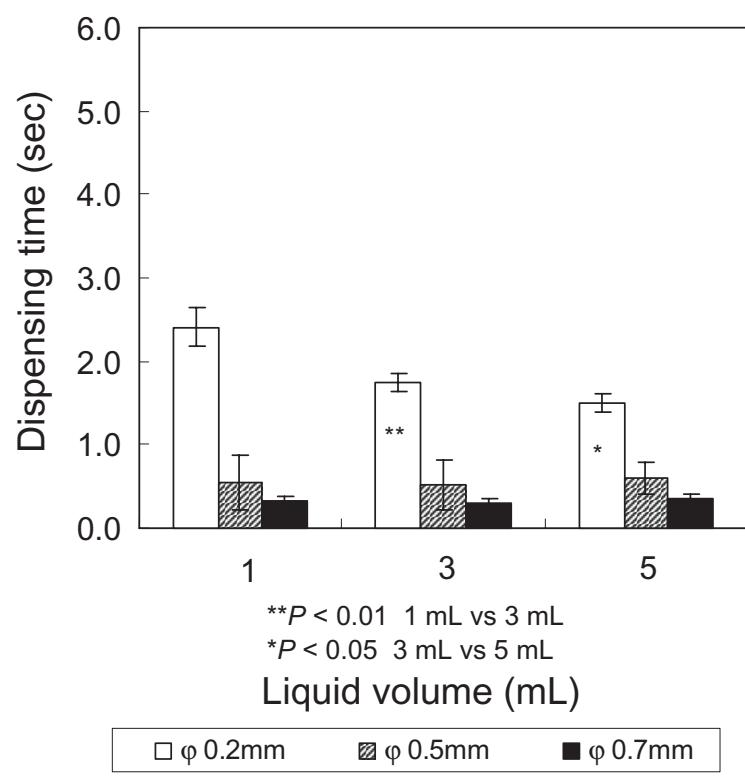

(B)

Figure 6 Dispensing time under condition of changing fluid volume, inner aperture diameter, and types of solution.

Notes: Dispensing time (mean \pm SD) under a condition of fixed internal nozzle volume $\left(30 \mathrm{~mm}^{3}\right)$ and pressure thrust load ( $\left.0.05 \mathrm{MPa}\right)$, and variable fluid volumes as well as inner aperture diameters. ( $\square: 0.2 \mathrm{~mm}, \square: 0.5 \mathrm{~mm}, \square: 0.7 \mathrm{~mm}$ ) (A: filtrate water, B: surfactant solution); error bars indicate standard deviation. Asterisks indicate statistically significant difference: $* P<0.05$; fluid volume of $3 \mathrm{~mL}$ vs fluid volume of $5 \mathrm{~mL}$, **P $<0.0$; fluid volume I mL vs fluid volume of $3 \mathrm{~mL}$.

\section{Discussion}

The dispensing time was mostly influenced by the inner aperture diameter (inner structure of nozzles) when it was measured by using eye dropper bottle models, solution models, and a newly developed dispensing time measuring apparatus.

The time to put a drop of ophthalmic solution into the eye through the instillation movement was thought to be influenced by features of the eye dropper bottles and their contents, as well as the strength applied to the bottle by users. However, few investigators have studied about them. In this study, we prepared eye dropper bottle models and solution models, focused on the dispensing time, and investigated the factors that influence it. To minimize the effect of the drop size on the dispensing time, the shape and materials of the eye dropper bottle models and outer diameter of a nozzle were fixed. On the other hand,

Table I Regression analysis regarding the dispensing time

\begin{tabular}{|c|c|c|c|c|c|}
\hline \multicolumn{3}{|c|}{ Filtrate water } & \multicolumn{3}{|c|}{ Surfactant solution } \\
\hline $\begin{array}{l}\text { Explanatory } \\
\text { variables }\end{array}$ & $\mathbf{R}^{2}$ & $P$ value & $\begin{array}{l}\text { Explanatory } \\
\text { variables }\end{array}$ & $\mathbf{R}^{2}$ & $P$ value \\
\hline$\overline{\mathrm{IAD}}$ & 0.46 & $<0.0001$ & IAD & 0.56 & $<0.0001$ \\
\hline ISV & 0.08 & $<0.0001$ & PTL & 0.04 & $<0.0001$ \\
\hline PTL & 0.06 & $<0.0001$ & ISV & 0.03 & $<0.0001$ \\
\hline- & - & - & $\mathrm{FV}$ & 0.03 & $<0.0001$ \\
\hline
\end{tabular}

Notes: Step-wise multiple linear regression analysis was performed to two types of solution models, with dispensing time as response variable.

Abbreviations: FV, fluid volume; IAD, inner aperture diameter; ISV, internal space volume; $P$ value, probability of $F$ value; PTL, pressure thrust load; $R^{2}$, coefficient of determination. the bottle models were molded with six types of inner aperture diameter, and three types of internal nozzle volume.

In practical settings, the speed to push eye dropper bottles could be varied depending on the materials and thickness of bottles. We thought the pressure to push dropper bottles was greatly related to the instillation performance of ophthalmic solutions. Therefore, we designed the apparatus so that we could control the pressure to push bottles. In addition, we investigated the dispensing time with using the eye dropper bottle model whose material and thickness were constant.

Fluid elements differ depending on ophthalmic solutions. Therefore, we used the following two types of test solutions on measuring the dispensing time: filtrate water with high surface tension $(72.8 \mathrm{mN} / \mathrm{m})$ and surfactant solution with low surface tension $(39.4 \mathrm{mN} / \mathrm{m})$. The drop size of filtrate water measured according to a previous report was $42 \mathrm{mg}$ and that of surfactant solution was $32 \mathrm{mg} .{ }^{11}$ Furthermore, since content solution decreased when an ophthalmic solution was used, we prepared three different volumes of test solutions ( $5 \mathrm{~mL}, 3 \mathrm{~mL}, 1 \mathrm{~mL}$ ) for this experiment. With the dispensing time measuring apparatus used in this study, three types of pressure thrust load (the pressure of air cylinder to push an eye dropper bottle model) could be used, and the distance between the tip of nozzle and the eye was virtually replicated. Therefore, we believed this apparatus reflected well the actual instillation movements.

With filtrate water, the dispensing time at pressure thrust load of $0.03 \mathrm{MPa}$ significantly increased from 
$1.1 \pm 0.5$ seconds to $4.6 \pm 1.1$ seconds when the inner aperture diameter was changed from $0.4 \mathrm{~mm}$ to $0.2 \mathrm{~mm}(P<0.0001)$. The dispensing time with inner aperture diameters of larger than $0.4 \mathrm{~mm}$ became constant (approximately 1 second). With surfactant solution, the dispensing time was approximately 2.5-fold lengthened when the inner aperture diameter was changed from $0.4 \mathrm{~mm}(0.8 \pm 0.4$ seconds $)$ to $0.2 \mathrm{~mm}$ $(2.2 \pm 0.3$ seconds) at pressure thrust load of $0.03 \mathrm{MPa}$. When pressure thrust load was large $(0.07 \mathrm{MPa})$, the solution flew out continuously with inner aperture diameters of larger than $0.4 \mathrm{~mm}$ and the dispensing time could not be measured.

Concerning the influence of internal volume of the nozzle, with filtrate water, the dispensing time using a small inner aperture diameter $(0.2 \mathrm{~mm})$ was lengthened as internal volume of the nozzle became larger $(1.6 \pm 0.4$ seconds with internal volume of $7 \mathrm{~mm}^{3}, 3.7 \pm 1.1$ seconds with $30 \mathrm{~mm}^{3}$, and $5.4 \pm 1.1$ seconds with $55 \mathrm{~mm}^{3}$ ). However, the dispensing time showed smaller changes as the inner aperture diameter became larger $(0.5 \mathrm{~mm}$ and $0.7 \mathrm{~mm})$. The results with surfactant solution were same as above.

Ophthalmic solutions are instilled when air pressure inside of the bottle is increased by the strength to push the bottle. The amount of air inside of the bottle is relatively larger when the amount of solution is smaller. Therefore, the dispensing time was thought to be quicker when the amount of solution in the bottle was smaller. In this study, the dispensing time significantly decreased from $2.4 \pm 0.2$ seconds to $1.5 \pm 0.1$ seconds when the fluid volume increased from $1 \mathrm{~mL}$ to $5 \mathrm{~mL}$ (surfactant solution, the inner aperture diameter: $0.2 \mathrm{~mm}$ ). However, with other inner aperture diameters, the dispensing time was not significantly different among fluid volumes. As a consequence, the inner aperture diameters influenced the dispensing time more than the fluid volumes.

Multiple regression analysis was performed to evaluate the size of effect of the each explanatory factor investigated in this study. When the dispensing time was regarded as a response variable, the factor that influenced the dispensing time most was the inner aperture diameter in both filtrate water and surfactant solution, and it was confirmed that its influence on the dispensing time was large.

Clinical Ophthalmology

\section{Publish your work in this journal}

Clinical Ophthalmology is an international, peer-reviewed journal covering all subspecialties within ophthalmology. Key topics include: Optometry; Visual science; Pharmacology and drug therapy in eye diseases; Basic Sciences; Primary and Secondary eye care; Patient Safety and Quality of Care Improvements. This journal is indexed on Submit your manuscript here: http://www.dovepress.com/clinical-ophthalmology-journal
Especially in the chronic treatment with ophthalmic solutions such as for glaucoma, improvement of operability of eye dropper bottles might influence the patient adherence. On the other hand, among the factors investigated in this study, fluid elements of the ophthalmic solution could not be easily changed because they were determined as a result of formulation optimization. The fluid volume and pressure thrust load were the factors depending on the users, and we could not directly control them. However, the inner aperture diameter could be controlled by devising the design of eye dropper bottles.

Our results in this report might provide a concrete idea to improve eye dropper bottles for better operability, which could influence the patient adherence to the ophthalmic treatments.

\section{Disclosures}

The authors report no conflicts of interest in this work.

\section{References}

1. Santvliet LV, Ludwig A. Dispensing eye drops from flexible plastic dropper bottles. Part III: Comparison between volunteers and elderly patients. Pharm Ind. 1999;61:276-280.

2. Kuramoto M, Higami T, Takahashi Y, et al. Study on the usability of ophthalmic solutions (I) - The variation in squeezing force and drop volume. Jpn J Pharm Health Sci (Iryouyakugaku). 2004;30:13-19.

3. Stewart WC, Sine C, Cate E, Minno GE, Hunt HH. Daily cost of $\beta$-adrenergic blocker therapy. Arch Ophthalmol. 1997;115:853-856.

4. Rouland JF, Le Pen C, Pinto CG, Berto P, Berdeaux G. Costminimisation study of dorzolamide versus brinzolamide in the treatment of ocular hypertension and primary open-angle glaucoma in four European countries. PharmacoEconomics. 2003;21:201-213.

5. Ikeda H, Sato E, Kitaura T, Fukuchi H, Kimura Y, Kihira K. Daily cost of ophthalmic solutions for treating glaucoma in Japan. Jpn J Ophthalmol. 2001;45:99-102.

6. Gaynes BI, Singa RM, Schaab G, Sorokin Y. Impact of administration angle on the cost of artificial tear solutions: does bottle positioning minimize wastage? J Ocul Pharmacol Ther. 2007;23:196-201.

7. Santvliet LV, Ludwig A. Dispensing eye drops from flexible plastic dropper bottles. Part I: Influence of the packaging characteristics. Pharm Ind. 1999;61:92-96.

8. Brown RH, Hotchkiss ML, Davis EB. Creating smaller eyedrops by reducing eyedropper tip dimensions. Am J Ophthalmol. 1985;99:460-464.

9. Santvliet VL, Ludwig A. Influence of the dropper tip design on the size of eye-drops. Pharm Ind. 2001;63:402-409.

10. Santvliet LV, Ludwig A. Determinants of eye drop size. Surv Ophthalmol. 2004;49:197-213.

11. Yoshikawa K, Yamada H. Drop volume, rigidity and required squeezing force of glaucoma ophthalmic solution containers. Jpn J Clin Ophthalmol (Rinshoganka). 2002;56:1587-1593.
PubMed Central and CAS, and is the official journal of The Society of Clinical Ophthalmology (SCO). The manuscript management system is completely online and includes a very quick and fair peer-review system, which is all easy to use. Visit http://www.dovepress.com/ testimonials.php to read real quotes from published authors. 